\title{
OS QUILOMBOS PERANTE O STF: A EMERGÊNCIA DE UMA JURISPRUDÊNCIA DOS DIREITOS ÉTNICOS (ADIN 3.239-9)
}

\section{RESUMO}

O STF APRECIARÁ ESTE ANO A ADIN N 3.239-9, NA QUAL SE DISCUTE A INTERPRETAÇÃO DO DIREITO DAS COMUNIDADES REMANESCENTES DE QUILOMBOS À TITULAÇÃO DE SUAS TERRAS (ART. 68 DO ADCT). PARA ALÉM DE PRENUNCIAR IMPACTOS SOCIAIS SOBREMODO RELEVANTES, NOTADAMENTE NO MERCADO DE TERRAS, ESSA AÇÃO RECOLOCA A CORTE SUPREMA BRASILEIRA FACE AOS DILEMAS DA JURISDIÇÃO CONSTITUCIONAL, TAIS COMO A SUA LEGITIMIDADE DEMOCRÁTICA, O SEU COMPROMISSO COM A CONCRETIZAÇÃO DOS DIREITOS FUNDAMENTAIS, ALÉM DA NECESSIDADE DE FORÇÁ-LA A PERSCRUTAR AS CONSEQUÊNCIAS MATERIAIS DE SUAS DECISÕES. A PARTIR DA DEMONSTRAÇĀO DA TESE DA FUNDAMENTABILIDADE DO DIREITO ÀS TERRAS QUILOMBOLAS E DA CRÍTICA ÀS TEORIAS LIBERAL-POSITIVISTAS DA JURISDIÇÃO E DA INTERPRETAÇÃO, ESTE ARTIGO VISA DEMARCAR AS QUESTÕES PRINCIPAIS DESSE PROCESSO JUDICIAL, CUJO ENFRENTAMENTO SE IMPÕE, SEGUNDO MÉTOdOS HERMENÊUTICOS ADEQUADOS, SE O TRIBUNAL QUISER CHEGAR A UM PROVIMENTO FINAL EFETIVO, ISTO É, SER CAPAZ DE PROMOVER A PACIFICAÇÃO SOCIAL E PROMOVER A EFICÁCIA DOS DIREITOS FUNDAMENTAIS, QUE CONSUBSTANCIAM A RAZÃO ÚLTIMA DA FUNÇÃO JURISDICIONAL NO CONTEXTO DO Estado Constitucional.

\section{PALAVRAS-CHAVE}

HERMENÊUTICA CONSTITUCIONAL; DIREITOS ÉTNICOS E CULTURAIS; TERRAS QUILOMBOLAS.

\author{
João Carlos Bemerguy Camerini
}

THE QUILOMBOS BEFORE SUPREME COURT: THE EMERGENCE OF AN ETHNIC RIGHTS JURISPRUDENCY (ADIN 3.239-9) ETHNIC RIGHTS JURISPRUDENCY (ADIN $3.239-9)$

\begin{abstract}
THIS YEAR, THE BRAZILIAN SUPREME COURT WILL JUDGE THE DIRECT ACTION OF UNCONSTITUTIONALITY 3239-9, WHICH DISCUSSES THE CORRECT INTERPRETATION OF THE RIGHT OF QUILOMBO COMMUNITIES TO THEIR TERRITORIES (ARTICLE 68 OF THE TRANSITORY CONSTITUTIONAL PROVISIONS ACT). THE DECISION OF THIS PROCESS WILL BRING SOCIAL IMPACTS, ESPECIALLY IN THE LAND MARKET, AND WILL COMPEL THE COURT TO FACE THE DILEMMAS OF CONSTITUTIONAL JURISDICTION, SUCH AS ITS DEMOCRATIC LEGITIMACY, ITS COMMITMENT TO THE REALIZATION OF FUNDAMENTAL RIGHTS AND THE PROBLEM OF MATERIAL CONSEQUENCES OF HARD CASES DECISIONS. BASED ON THE THESIS THAT THE QUILOMBO TERRITORIES ARE FUNDAMENTAL RIGHTS, THIS TEXT SEEKS TO DEMARCATE THE KEY ISSUES OF THIS LAWSUIT, WHOSE ANALYSIS IS IMPOSED, ACCORDING TO APPROPRIATE HERMENEUTICAL METHODS, IF THE COURT WANTS TO COME TO AN EFFECTIVE JURISDICTIONAL PROVIDING, THAT IS, CAPABLE OF PROMOTING SOCIAL PEACE AND PROMOTE THE EFFECTIVENESS OF FUNDAMENTAL RIGHTS, WHICH EMBODY THE ULTIMATE REASON OF THE JUDICIAL FunCtion IN THE CONTEXT OF THE CONSTITUTIONAL STATE.

\section{KEYWORDS}

CONSTITUTIONAL HERMENEUTICS; ETHNIC AND CULTURAL RIGHTS; QUILOMBO TERRITORIES.
\end{abstract}

\section{INTRODUÇÃO: O STF FACE AOS QUILOMBOS}

Será julgada este ano, ${ }^{1}$ pelo Supremo Tribunal Federal (STF), a ação direta de inconstitucionalidade (ADIn) n ${ }^{\circ} 3.239-9$, ajuizada em 2004, pelo Partido da Frente Liberal 
(PFL), hoje denominado Democratas (DEM), visando obter declaração de inconstitucionalidade do Decreto Federal $\mathrm{n}^{\circ}$ 4.887/03, editado pelo Governo Lula, que regulamenta o procedimento administrativo de identificação, reconhecimento, delimitação, demarcação e titulação das terras ocupadas por remanescentes das comunidades de quilombos de que trata o artigo 68 do Ato das Disposições Constitucionais Transitórias (ADCT). ${ }^{2}$

A interpretação do artigo 68 do ADCT é matéria jamais apreciada pelo Tribunal Constitucional brasileiro, que terá de forjar um posicionamento inédito face às poderosas agências políticas, econômicas e sociais interessadas na prevalência de uma interpretação que confira maior ou menor eficácia e extensão a esse direito constitucional. Fora das vias institucionais, tais antagonismos exprimem-se em conflitos sociais deflagrados no espaço urbano e rural brasileiro, os quais parecem, pelo menos por enquanto, ofuscar as iniciativas de tratamento teórico-doutrinário do tema.

De fato, o discurso jurídico sobre a propriedade dos remanescentes de quilombo hoje é resultado mais dos dispêndios de capital simbólico (Bourdieu, 2009) para sedimentação de uma "verdade jurídica” do que de qualquer empreendimento doutrinário sistemático nesse sentido. A jurisprudência reflete esse estado do campo ao se revelar tão contraditória e flutuante quanto à própria trama histórica que a produz.

Nessas condições, hodiernamente, teses absolutamente discrepantes sobre a interpretação do artigo 68 são postas em circulação no campo, diretamente influenciadas por fatores externos à racionalidade jurídica, gerando ainda mais incerteza social quanto à aplicação da norma constitucional. Os efeitos da ausência de conhecimento sobre o tema são intensificados pelo calor das demandas sociais que obrigam o Judiciário a se pronunciar sobre matéria, a despeito da lacuna teórica e jurisprudencial existente no direito brasileiro, daí surgindo recorrentes decisões contraditórias, mal fundamentadas ou até mesmo aberrações jurídicas.

Como tendência contraposta a esse quadro, anota-se o aparecimento, na primeira década do século XXI, de um novo campo da prática e da ciência jurídica, o direito étnico, com a proposta de enfrentar temas relacionados à garantia de direitos fundamentais das chamadas comunidades e povos tradicionais, minorias sociais, povos indígenas e tribais, etc., e desenvolver métodos próprios de interpretação das normas jurídicas correlatas, existentes em âmbito nacional e internacional.

Nessas pesquisas assume especial relevância o problema do reconhecimento das terras tradicionalmente ocupadas, estando dentre estas os territórios quilombolas. Contudo, apesar desses avanços no plano doutrinário em direção à consolidação de um campo dos direitos étnicos, ainda está para nascer uma jurisprudência que conheça e aplique esses textos jurídicos.

Assim definidos os contornos da problemática jurídica das terras quilombolas, que a Corte Suprema do país está em vias de apreciar, o presente artigo visa, para além de tangenciar algumas nuances da ação constitucional acerca dos quilombos, 
propor e demarcar temas a serem necessariamente enfrentados pelo STF, se o tribunal quiser que sua prestação jurisdicional logre seus objetivos, consubstanciando tutela jurisdicional eficaz.

A ressalva justifica-se na medida em que uma das principais formas de se negar a tutela jurisdicional consiste na postura judicante propriamente positivista de excluirse do debate processual questões não programadas nos textos jurídicos consagrados (legais, jurisprudenciais, doutrinários) ou inviabilizar-se o acesso a justiça sob pretextos formais.

Intuitivo que essa perspectiva afasta-se das concepções liberais do que seja a jurisdição, para entendê-la, em consonância com o constitucionalismo pós-positivista, como instância de poder prioritariamente compromissada com a prevalência dos direitos fundamentais (Marinoni, 2006). E não são poucos, ademais, os processualistas de escol que se reportam à finalidade da jurisdição, no Estado Democrático de Direito, como sendo indissociável da "pacificação social" (Cintra, Grinover, Dinamarco, 2004, p. 23ss).

É nesse escopo de chegar ao cerne do problema das terras quilombolas, superando eventuais entraves e distorções do formalismo jurídico, e permitir a realização da finalidade da jurisdição, no sentido pleno e neoconstitucional da expressão, que estas notas sublinham algumas questões a serem "levadas a sério" quando do julgamento da ADIn $n^{\circ}$ 3.239-9, vale repetir, se o STF desejar ver reinar nos quilombos - e no campo brasileiro - a paz.

\section{Pontos controvertidos da ADIN N ${ }^{\circ} 3 \cdot 239-9$}

Parece-me importante fixar, inicialmente, o que se discute acerca do Decreto regulamentador da titulação das terras quilombolas em sede de controle abstrato de constitucionalidade. O relatório do próprio relator ministro Cézar Peluso demarca as regiões da contenda.

Em primeiro lugar, a petição inicial aduz que "o Decreto $n^{\circ} 4.887 / 03$ invade esfera reservada à lei”, 3 alegação que, ao meu sentir, consiste na proposição fundamental da argumentação do autor, pois sobre ela está edificada toda a estratégia discursiva posteriormente desenvolvida. De acordo com esse argumento, o ato normativo impugnado estaria eivado de inconstitucionalidade formal por ter exorbitado de seu poder/função estritamente regulamentar, transmudando-se no que os administrativistas chamam de decreto autônomo. ${ }^{4}$

Em complemento do raciocínio supra, sustenta-se que, ao consagrar direitos e obrigações não previstos em lei, o decreto teria infringido o princípio da legalidade (art. 5, II, CF/88) e o princípio republicano da separação dos poderes (art. $2^{\circ}$, CF/88), erigindo-se, sobre essas premissas, a tese da eficácia limitada do artigo 68, visto que seus efeitos dependeriam de lei regulamentar, conforme a classificação de 
José Afonso da Silva (2007), tese defendida com competência em parecer elaborado pelo ex-ministro do STF e renomado civilista Carlos Mário da Silva Velloso, ${ }^{5}$ a pedido da empresa Aracruz Celulose, que possui interesse no processo.

Em seguida, há o argumento de que o Decreto $\mathrm{n}^{\circ}$ 4.887/03 introduziu hipótese desapropriação não prevista no regime constitucional e legal vigente, qual seja, a desapropriação para fins de titulação de terras quilombolas. A inicial afirma que, se se quisesse inferir do enunciado do artigo 68 que, em havendo pretensões sobrepostas sobre um mesmo imóvel de domínio privado, seria o caso de promover desapropriação, isso deveria estar literalmente expresso na Constituição ou em lei.

Ocorre que a interpretação literal-gramatical, quando utilizada como quase única via de acesso ao significado do artigo 68, resulta em conclusões contraditórias e até teratológicas, ofensivas à dignidade humana, como a de que os quilombolas expulsos de suas terras, através de roubos, esbulhos e violências, não reaveriam jamais seu lugar, por não estarem na posse do mesmo na data da promulgação da Carta Magna de 1988. De modo que parece militar em contra essa tese o princípio da unidade da Constituição.

Continuando o exame da perspectiva construída pelo autor, os demais pontos controversos apareceriam, em segundo plano, precisamente como aquelas matérias cuja disciplina seria competência do Legislativo, quais sejam: (1) a definição o sujeito de direito beneficiário do artigo 68, os remanescentes das comunidades quilombolas e; (2) a definição do objeto do direito designado propriedade definitiva das terras que estejam ocupando. Isto é, o conteúdo, o grau de eficácia e a extensão dessas categorias jurídicas constitucionais inéditas: eis o que há, afora o enfoque imprimido pelos proponentes, de realmente importante na demanda em análise, que deve ser ventilado por ocasião da decisão, sob pena de uma prestação jurisdicional em certo sentido ilusória.

\section{A TESE DA FUNDAMENTALIDADE DO DIREITO Às TERRAS QUILOMBOLAS}

Como afirmei anteriormente, até o presente não existem princípios jurídicos e dispositivos normativos suficientemente reconhecidos no direito brasileiro que possam organizar minimamente aquilo que é possível ser dito sobre o artigo 68, delimitando também, por via reflexa, as regiões epistêmicas do falso, do impensável e do teratológico (Camerini, 2010, p. 133). Enquanto não ocorrer tal estruturação propriamente disciplinar (Foucault, 1999, p. 30), o discurso jurídico quilombola permanecerá sem autonomia e mais diretamente exposto a ingerências políticas, vagueando por entre diversos aportes teóricos, sendo, nessas condições, quase certa, a proliferação, nas paragens do Judiciário, de decisões incongruentes ou mal fundamentadas.

Nos últimos vinte anos, o debate sobre a natureza e o conteúdo do direito territorial quilombola não permaneceu estanque, tendo assumido diferenciadas configurações, sem que haja ainda consenso quanto aos contornos desse novo direito introduzido pela Constituição de 1988 . 
Foram já os quilombos definidos, sob a óptica privatista, ora como direito indenizatório patrimonial, individual e disponível, ora como uma espécie de usucapião de prazo centenário. Na perspectiva agrarista, foram vistos como categorias da política de reforma agrária do Estado brasileiro. Pelo enfoque constitucionalista, sustentou-se sua qualidade de direitos humanos fundamentais, ações afirmativas ou, ainda, de patrimônios históricos e culturais. E, afinal, se fôssemos encerrá-los em qualquer destas classificações, talvez restassem descaracterizados (Camerini, 2010, p. 168ss).

Diante desse panorama, é possível imaginar quão relevante para o campo dos direitos quilombolas será a manifestação do STF na ação constitucional em análise e também em que medida a validade da tese da eficácia limitada dos autores depende, essencialmente, de que se descubra qual a natureza jurídica do direito plasmado no artigo 68 do ADCT, pois, se o artigo 68 abrigar um direito fundamental, como defende a maioria dos especialistas na matéria, além do Ministério Público Federal em seu parecer pela improcedência da ADIn n ${ }^{\circ} 3.239-9$, será uma razão forte em favor da tese da eficácia imediata da norma constitucional, que traduz o principal argumento em defesa do Decreto $n^{\circ} 4.887 / 03$, na medida em que os direitos fundamentais se definem, no quadro do constitucionalismo contemporâneo, por serem "posiciones tan importantes que su otorgamiento o no otorgamiento no puede quedar en manos de la simple mayoría parlamentaria” (Alexy, 1993, p. 432).

A propósito, salienta Shiraishi Neto (2004, p. 159) que "o avanço na compreensão em torno da aplicação do artigo 68 do ADCT decorre de que esse direito é compreendido como sendo direito fundamental”, quer dizer, muita coisa muda conforme se conceitue ou não os quilombos como direitos fundamentais. Disso depende, por exemplo, a aplicação dos cânones da hermenêutica dos direitos fundamentais ao artigo 68 e - o que é mais determinante -, a incidência do seguinte preceito constitucional: "As normas definidoras dos direitos e garantias fundamentais têm aplicabilidade imediata” (art. $5^{\circ}, \S 1^{\circ}$ da CF/88).

$\mathrm{Na}$ busca de saber se os quilombos possuem, em nosso sistema jurídico-constitucional brasileiro, status de direitos fundamentais, a primeira indagação a ser feita é se há fundamentos que justifiquem essa condição e se o conteúdo do artigo 68 atrai de fato essas razões. O caminho mais prático nessa investigação é perguntar se as ações, situações ou relações sociais que compõem o fenômeno dos territórios quilombolas estão protegidas por algum direito fundamental consagrado na Constituição ou, na linguagem técnica, se tais posições constituem suporte fático enquadrável no âmbito de proteção de algum desses direitos.

Uma noção introdutória dos dois conceitos por último destacados se obtém a partir da definição dada por Gilmar Mendes (2000, p. 211): "O âmbito de proteção de um direito fundamental abrange os diferentes pressupostos fáticos (Tatbeständen) contemplados na norma jurídica (...) e a consequência comum, a proteção fundamental”. 
É oportuno acrescentar, ainda fixando os pressupostos do debate sobre o fundamento e o conteúdo do direito às terras quilombolas, que se deve desde logo descartar qualquer argumento que vise diminuir o valor jurídico das terras quilombolas pelo fato do artigo 68 integrar o corpo das normas constitucionais transitórias.

A complexidade da questão não permite essa resposta baseada em critérios topológico-textuais, sobretudo em razão da cláusula de abertura prevista na própria Carta Magna: “Os direitos e garantias expressos nesta Constituição não excluem outros decorrentes do regime e dos princípios por ela adotados, ou dos tratados internacionais em que a República Federativa do Brasil seja parte" (art. $5^{\circ}, \S 2^{\circ}$, CF/88). A essa solução fácil, oponho que há que se levar os quilombos a sério.

\section{I QUILOMBOS COMO DIREITOS CULTURAIS: REFLEXOS SOBRE OS VALORES DA AUTODETERMINAÇÃO DOS POVOS E NA DIGNIDADE HUMANA}

No sentido de reforçar a tese da natureza jusfundamental do direito às terras quilombolas, a maioria da doutrina - nas ciências sociais e no direito -, afirma categoricamente que o artigo 68 traduz, em primeiro lugar, concretização de direitos culturais das comunidades remanescentes de quilombos.

Consagrados em tratados internacionais e insculpidos nos artigos 215 e 216 da Constituição Federal do Brasil, os direitos culturais abrangem o chamado patrimônio cultural material e imaterial, donde resulta a garantia dos diferentes segmentos formadores da sociedade brasileira a terem protegidos seus "modos de criar, fazer e viver", mandamento constitucional cuja efetividade depende, no caso das comunidades quilombolas, da titulação de suas terras.

Além disso, situar os quilombos como manifestações abrangidas pelo conceito de patrimônio cultural justificaria o uso da desapropriação - instrumento expressamente previsto no artigo $216, \S 1^{\circ}$, para proteção desse bem jurídico ${ }^{6}$ - de áreas privadas inseridas nas terras quilombolas, possibilidade esta refutada vigorosamente pelas classes proprietárias de terras que se manifestaram na ADIn n ${ }^{\circ}$ 3.239-9.

No mesmo passo, a titulação das terras ocupadas pelos remanescentes das comunidades de quilombos, assim vistas como territórios tradicionais de povos culturais e - em maior ou menor medida - politicamente distintos, é também apontada por diversos analistas como sendo procedimento decorrente do direito à autodeterminação dos povos, consagrado nos dois Pactos Internacionais de Direitos Humanos da ONU e na própria Constituição Federal (art. $4^{\circ}$, III da CF/88).

Contudo, a interpretação dos direitos territoriais das comunidades tradicionais, sobretudo indígenas, à luz desse direito de conteúdo prioritariamente político-territorial, tem se mostrado problemática e cercada de intensa comoção social, além de não gozar de receptividade no Supremo Tribunal Federal, como será discutido logo a seguir. Sem embargo, não apenas o direito à autodeterminação protege a cultura e os territórios da comunidade tradicionais, em nível supranacional. ${ }^{7}$ 
Dentre os mais importantes tratados internacionais imediatamente aplicáveis pelos tribunais brasileiros ao contexto quilombola, estão o Pacto Internacional dos Direitos Econômicos, Sociais e Culturais de 1966, a Convenção 169 da Organização Internacional do Trabalho (OIT), sobre povos indígenas e tribais em países independentes, de 1989, a Convenção da Diversidade Biológica (CDB) de 1992, a Convenção sobre a Proteção e a Promoção da Diversidade das Expressões Culturais de 2005 e a Declaração Universal sobre Diversidade Cultural de 2001, as duas últimas celebradas no âmbito da Unesco. ${ }^{8}$ Essa última declaração internacional, em particular, tem o mérito de positivar, em seu artigo $4^{\circ}$, a já intuitiva conexão entre a liberdade cultural e a dignidade humana:

A defesa da diversidade cultural é um imperativo ético, inseparável do respeito à dignidade humana. Ela implica o compromisso de respeitar os direitos humanos e as liberdades fundamentais, em particular os direitos das pessoas que pertencem a minorias e os dos povos autóctones. Ninguém pode invocar a diversidade cultural para violar os direitos humanos garantidos pelo direito internacional, nem para limitar seu alcance.

Contudo, em desprestígio à força de argumentação dos direitos à cultura e à autodeterminação como fundamentos do direito aos territórios tradicionais no contexto quilombola e no de outras realidades sobre as quais seu espectro protetivo se irradia, é pesaroso constatar que a determinação do conteúdo, alcance e eficácia desses importantes capítulos de nossa democracia constitucional e pretensamente multicultural ainda perfaz uma lacuna na jurisprudência do STF.

No julgamento do caso da Terra Indígena Raposa Serra do Sol, o Tribunal Constitucional brasileiro fez questão de desvestir os territórios tradicionais, em particular os indígenas, de qualquer conotação política, inaugurando assim uma tendência jurisprudencial de mutilação das culturas tradicionais, privando-as de um de seus aspectos essenciais, nos seguintes termos:

Somente o "território" enquanto categoria jurídico-política é que se põe como o preciso âmbito espacial de incidência de uma dada Ordem Jurídica soberana, ou autônoma. O substantivo "terras" é termo que assume compostura nitidamente sociocultural, e não política. A Constituição teve o cuidado de não falar em territórios indígenas, mas, tão só, em "terras indígenas”. A traduzir que os "grupos", “organizações", "populações" ou "comunidades" indígenas não constituem pessoa federada. Não formam circunscrição ou instância espacial que se orne de dimensão política. Daí não se reconhecer a qualquer das organizações sociais indígenas, ao conjunto delas, ou à sua base peculiarmente antropológica a dimensão de instância transnacional. ${ }^{9}$ 
Baseado numa fictícia dissociação entre cultura e política e num entendimento estritamente gramatical do vocábulo "terra”, esse equivocado posicionamento nega, com evidente violência simbólica, o óbvio ululante, aquilo que as descrições antropológicas das culturas indígenas e tradicionais unanimemente sublinham, vale dizer, a existência de instituições políticas e jurídicas locais, legítimas - pois o pluralismo é incentivado pelo Estado Multicultural -, efetivas e inextricáveis da organização social desses povos.

Os territórios tradicionais, indígenas ou não, constituem, dessarte, unidades sociais integrais, dotadas de aspectos econômicos, culturais e, sem dúvida, políticos. Se hoje se subtrai, a priori, desses povos o direito à autodeterminação, certamente não é - estão aí os etnólogos para confirmá-lo -, porque tais realidades político-culturais não existam, mas antes porque, assim diria Boaventura de Sousa Santos, há um esforço ativo no sentido de produzi-las como não existentes (Santos, 2002, p. 253), inclusive com o uso da força coercitiva e simbólica do direito e com o recurso a uma ideia de soberania - irmã de outra noção, a de segurança nacional - que, de um lado, sempre impediu o avanço do sistema de proteção aos direitos humanos no plano internacional e, de outro, põe-se a sufocar as manifestações culturais e a autonomia social em âmbito interno.

Ao se apegar a essa ideia tão ultrapassada quanto infactível do que seja soberania, o Supremo vulnerabiliza o direito frente à crítica habermasiana que o acusa de ser sistema promotor da chamada colonização do mundo da vida, que gera a destruição das relações sociais comunicativas ancoradas em domínios sociais constituídos por elementos simbólico-subjetivos, como a cultura, a tradição, a religião, etc., devido à substituição destas estruturas de mediação das interações humanas por outras erigidas segundo uma racionalidade autorreferida com respeito a fins, notadamente a do Estado (burocracia) e a da economia (dinheiro), sendo características desse processo a uniformização, a coisificação e a mecanização das relações intersubjetivas (Habermas, 1992, p. 469).

O julgamento da ADIn n ${ }^{\circ}$ 3.239-9, em que provavelmente se definirá o conteúdo do direito às terras quilombolas seria, portanto, momento propício à evolução da jurisprudência da Corte Constitucional brasileira sobre os direitos étnicos, que encontra-se ainda em formação, no sentido de reconhecer, ao menos em um grau razoável, do direito dessas comunidades à autodeterminação e à liberdade cultural, com suas repercussões sociais, econômicas e políticas.

\subsection{A neCeSSÁRia CONSIDERAÇÃo da CONVENÇÃo i69 dA OIT}

Dentro da notável constelação de normas internacionais sobre direitos culturais, merece destaque a Convenção 169 da OIT (promulgada pelo Decreto n ${ }^{\circ}$ 5.051/2004), porquanto estabelece um substancioso e detalhado regime de direitos territoriais específicos dos direitos dos povos culturalmente diferenciados, chamados "indígenas" ou "tribais", sendo seu exame indispensável para o desfecho da ADIn n 3.239-9. 
Com efeito, todas as objeções que, naquela ação constitucional, enfatizaram a necessidade de regulamentação do artigo 68, tais como a necessidade de prever "quem seriam os remanescentes de quilombos" e/ou "como se definiriam suas terras", restarão plenamente contornadas se imperar a aplicabilidade imediata desse tratado internacional.

A Convenção 169 cristaliza um verdadeiro regime jurídico dos direitos étnicos. Em especial, consagra "consciência de sua identidade" como critério fundamental para determinação da etnicidade (art. $1^{\circ}$, itens 1 e 2), sem prejuízo, é bem verdade, da consideração de outros parâmetros. No caso dos quilombos, por exemplo, o Decreto $n^{\circ} 4.887 / 03$ (art. $2^{\circ}$ ) densifica o critério da autodefinição com características e conteúdos próprios à etnicidade quilombola, como a "trajetória história própria", "relações territoriais específicas" e "presunção ancestralidade negra relacionada com a resistência à opressão histórica sofrida", tudo aferido através de laudo antropológico. ${ }^{10}$

No julgamento da Raposa Serra do Sol, o Supremo demonstrou avanços no entendimento da noção de etnicidade aplicada ao contexto indígena. Embora sem fazer referência à convenção ou discutir o critério da autodefinição, a Corte afirmou:

\section{O SIGNIFICADO DO SUBSTANTIVO “ÍNDIOS” NA CONSTITUIÇÃO} FEDERAL. O substantivo "índios” é usado pela Constituição Federal de 1988 por um modo invariavelmente plural, para exprimir a diferenciação dos aborígenes por numerosas etnias. Propósito constitucional de retratar uma diversidade indígena tanto interétnica quanto intraétnica. Índios em processo de aculturação permanecem índios para o fim de proteção constitucional. Proteção constitucional que não se limita aos silvícolas, estes, sim, índios ainda em primitivo estádio de habitantes da selva. ${ }^{11}$

Sem dúvida, o raciocínio aplicado aos "índios” comporta transposição para os "remanescentes de quilombos" ou "quilombolas", sobretudo na parte relativa às relações interétnicas e às ideias estigmatizadas sobre como deve parecer uma comunidade indígena ou quilombola, para que possa atrair proteção constitucional. Ao afastar as interpretações externas, colonialistas (como no conceito de quilombos vigente no Brasil Colônia e Império), biologizantes (como no termo silvícola), ou fundadas sobre dualismos geográficos (como na noção de isolamento), a Corte constrói o baldrame hermenêutico para o futuro reconhecimento do critério da autodefinição, que pressupõe respeito ao imaginário endógeno dos próprios sujeitos coletivos e de uma concepção dinâmica da história e da cultura.

Ademais, acerca do controverso significado do termo "terra", na semântica do direito étnico, a Convenção 169, em divergência expressa à orientação do STF, dispõe que: “A utilização do termo 'terras' nos artigos 15 e 16 deverá incluir o conceito 
de territórios, o que abrange a totalidade habitat das regiões que os povos interessados ocupam ou utilizam de alguma outra forma” (art. 13, item 2).

Os demais dispositivos garantem proteção ampla aos direitos territoriais dos grupos étnicos diferenciados, com ênfase no aspecto coletivo de suas territorialidades, mencionando, por exemplo: o respeito aos valores, culturas e elementos simbólicos e espirituais atrelados às terras ou territórios tradicionais (art. 13, itens 1); o direito de propriedade e posse sobre suas terras, inclusive áreas de uso não exclusivamente ocupadas por eles, bem como procedimentos adequados para resolução dos conflitos decorrentes dessa ocupação (art. 14, item 1 e 3); direito aos recursos naturais existentes em suas terras (art. 15); o direito à não remoção dos povos tradicionais de suas terras, salvo em casos excepcionais (art. 16, itens 1 e 2) e; o direito de retorno assim que cessada a causa do deslocamento (art. 16, item 3).

Além desses, o direito de consulta prévia e informada quando da discussão sobre atos legislativos ou administrativos suscetíveis de impactarem suas terras (art. $6^{\circ}$, item 1, a), deve ser compreendido harmonicamente com o artigo $7^{\circ}$, item 1 , adiante transcrito, ambos ressaltando de modo explícito o direito à autodeterminação garantido aos povos indígenas e tribais, dentre os quais sem dúvida figuram as comunidades quilombolas.

Os povos indígenas e tribais deverão ter o direito de decidir sobre suas prioridades no que se refere ao processo de desenvolvimento na medida em que afete suas vidas, crenças e bem estar espiritual, e às terras que ocupam ou utilizam de alguma forma, e de controlar, na medida do possível, seu próprio desenvolvimento econômico, social e cultural. Além disso, deverão participar da formulação, implementação e avaliação dos planos e programas de desenvolvimento nacional e regional suscetíveis de os afetar diretamente.

A análise aprofundada dos institutos da Convenção 169 excede a finalidade deste artigo, que é precipuamente demarcar questões de análise incontornável para a decisão da ADIn $n^{\circ}$ 3.239-9. Por agora, basta assinalar que as disposições supra não foram consideradas - ou foram frontalmente violados -, no caso da Raposa Serra do Sol, ${ }^{2}$ mas deveriam sê-lo no caso dos quilombos, a fim de lançar novas luzes ao problema do direito étnico, de que o texto convencional se ocupa de modo exaustivo.

\subsection{OS QUILOMBOS COMO DIREITO SOCIAIS: O ESTADO CORRETOR DAS DESIGUALDADES} MATERIAIS E OS IMPACTOS DA TITULAÇÃO QUILOMBOLA NO MERCADO DE TERRAS

Nos termos da Constituição e dos tratados internacionais mais importantes firmados pelo Brasil, todos os seres humanos, incluindo os descendentes de escravos, têm direitos sociais como a moradia, a alimentação e o trabalho, os quais compõem aquele patamar mínimo indispensável à garantia do valor magno da dignidade humana. Sob 
esse ponto de vista, as terras quilombolas materializam direitos universais, se bem que sua feição seja dada por uma clivagem cultural específica.

Ademais, o sentido do artigo 68 e do próprio Decreto ${ }^{\circ} 4.887 / 03$, que lhe confere viabilidade material, não se distancia dos objetivos constitucionais visados pelo artigo $3^{\circ}$ da $\mathrm{CF} / 88$, exortando o Estado à erradicação da pobreza e a progressiva redução das desigualdades sociais (inc. I), como caminhos para a construção de uma sociedade livre, justa e solidária (inc. III), promovendo o bem de todos, sem qualquer forma de discriminação (inc. IV). Esse dispositivo traduz a essência do princípio da igualdade material e o norte do dirigismo constitucional brasileiro, vinculante para os três poderes.

Adotando esse enfoque, a titulação das terras quilombolas trata de uma das iniciativas concretas previstas na própria Constituição Federal de ações afirmativas e compensatórias direcionadas a um segmento social - os grupos remanescentes da escravidão -, notoriamente fragilizado (discriminação positiva), vitimado pela discriminação étnico-racial e historicamente despojado de suas terras, cultura e dignidade, além do acesso a serviços públicos básicos de educação e saúde.

O mesmo supracitado precedente da Terra Indígena Raposa Serra do Sol, é justo assinalar, afora as críticas, consagrou interpretação avançada que vinculou os direitos indígenas à noção de "constitucionalismo fraternal”, conforme a expressão da Corte, e cujas bases estão evidentemente traçadas no artigo $3^{\circ}$ da Carta Magna. Faz-se importante transcrever esse excerto, não apenas por conter raciocínio perfeitamente transportável para o contexto quilombola, mas também porque nesse caso o STF transmitiu à sociedade o esboço de uma jurisprudência dos direitos étnicos e da solidariedade:

Os arts. 231 e 232 da Constituição Federal são de finalidade nitidamente fraternal ou solidária, própria de uma quadra constitucional que se volta para efetivação de um novo tipo de igualdade: a igualdade civil-moral de minorias, tendo em vista o protovalor da integração comunitária. Era constitucional compensatória de desvantagens historicamente acumuladas, a se viabilizar por mecanismos oficiais de ações afirmativas. No caso, os índios a desfrutar de um espaço fundiário que lhes assegure meios dignos de subsistência econômica para mais eficazmente preservar sua identidade somática, linguística e cultural. ${ }^{13}$

Além do frágil argumento topológico-textual, não há razão que impeça a analogia entre as terras indígenas e quilombolas, considerando que a trajetória histórica de ambos os segmentos sociais foi marcada por crimes contra a humanidade (genocídio, torturas, deslocamentos compulsórios) e, em particular, pelo esbulho ou privação de suas terras. Os dois grupos seriam destinatários, no dizer do STF, da "concretização constitucional do valor da inclusão comunitária pela via da identidade étnica”. ${ }^{14}$ 
Portanto, as iniciativas de titulação dos quilombos e demarcação de terras indígenas podem ser, na trilha do entendimento do Supremo, conceituadas políticas públicas portadoras de ações afirmativas, decorrentes do princípio da igualdade material, destinadas a compensar desigualdades sociais, fundiárias e culturais, com o plus normativo-eficacial de serem engendradas pela própria Constituição Federal.

Não custa recordar, de resto, em favor das políticas afirmativas tão em voga na atualidade, a verdade estatística amplamente difundida de que a desigualdade material, particularmente quanto à distribuição de renda, terras e outros direitos sociais, atende, dentre outros critérios discriminatórios, a um recorte étnico-racial, conforme enfatiza Flávia Piovesan:

Considerando os processos de "feminização" e "etnicização" da pobreza, percebe-se que as maiores vítimas de violação dos direitos econômicos, sociais e culturais, na experiência brasileira, são as mulheres e as populações afrodescendentes (...). Daí a necessidade de adoção, ao lado das políticas universalistas, de políticas específicas, capazes de dar visibilidade a sujeitos de direito com maior grau de vulnerabilidade, visando o pleno exercício do direito à inclusão social (Piovesan, 2004, p. 30-31).

Tenha-se em conta, ademais, que, num país de contradições como é o Brasil, uma das mais graves diz respeito à estrutura agrária nacional que conserva uma feição latifundiária e excludente que se reatualiza desde o período colonial. Nesse sentido, por serem descendentes de negros e camponeses, os quilombolas veem-se duplamente enquadrados nas estatísticas da desigualdade.

As projeções indicam um total entre 15 e 30 milhões de hectares de terras demandadas pelas comunidades remanescentes de quilombos, ${ }^{15}$ o que importa num impacto considerável no mercado de terras, na medida em que as terras quilombolas são registradas mediante título pro-indiviso, inalienável, impenhorável e imprescritível. Embora esses dados quantitativos não encontrem tradução direta na seara judicial, segundo Alfredo Wagner de Almeida (2005), é precisamente esse contexto econômico e político que explica o ferrenho conflito social ora transportado para os autos da ADIn $n^{\circ}$ 3.239-9, visto que "a expressão econômica desses mais de 30 milhões de hectares não pode ser menosprezada, sobretudo se observarmos sua incidência nas regiões de colonização mais antiga onde as terras são mais valorizadas do que naquelas de ocupação recente” (Almeida, 2005, p. 24).

Nesses termos, a política pública de titulação de terras quilombolas, bem assim a de demarcação de terras indígenas - que somam 111,5 milhões de hectares ${ }^{16}$-, sem se reduzirem a mero programa de reforma agrária, por possuírem fundamentos e procedimentos distintos, a ela, no entanto, se afinam como componentes do programa constitucional geral de correção das desigualdades sociais, em seu viés fundiário e 
étnico-cultural, de modo que a análise dos impactos políticos e econômicos de sua decisão também parece ser um capítulo relevante a ser abordado STF. Eis a oportunidade de uma decisão corretora da estrutura agrária latifundiária secular brasileira.

\subsection{Comunidades QUilombolas E O Direito humano de NÃo SER ESCRAVIZAdo}

Como ressaltei anteriormente, o caráter aberto do sistema jusfundamental brasileiro possibilita a vigência de direitos consagrados na dimensão internacional ou mesmo extraídos hermeneuticamente do todo constitucional. Tanto isso é verdade que não foi nenhum documento jurídico positivado o fundamento que, afinal, prevaleceu em favor das comunidades quilombolas na Assembleia Nacional Constituinte de 1987/88.

Antes de avançarmos nessa investigação, é preciso atenção para o que disse o antropólogo Arruti sobre a pobreza dos debates constituintes que marcaram a gênese do direito em comento:

A intenção do legislador, fantasmagoria recorrentemente citada nos textos de hermenêutica jurídica, dificilmente pode ser reivindicada como chave de compreensão dessa nova realidade. Ao tentarmos dar conteúdo sociológico a essa suposta “intenção", no caso do artigo 68, encontramos pressupostos obscuros e confusos, um conhecimento muito limitado da realidade que nele se faria representar e uma discussão que, em momento algum, apontou para o futuro, mas sempre para o passado (Arruti, 2006, p. 67).

A despeito de não haver reparos a essa conclusão, se quisermos realmente saber algo de seguro sobre a intentio legislatoris, no que tange ao artigo 68 do ADCT, podese dizer que os historiadores do direito às terras quilombolas concordam que a reivindicação da existência de uma "dívida histórica" do Estado brasileiro para com os remanescentes de quilombos, a ser devidamente reparada, "parece ter sido o argumento mais forte, sem procurar entrar no mérito, que prevaleceu no transcurso dos debates dos constituintes em 1988” (Silva, 1997a, p. 12; Arruti, 2006, p. 68; Camerini, 2010, p. 48).

Portanto, a despeito de todos os direitos positivados que manifestamente incidem sobre os quilombos, veio prevalecer, por ocasião da afirmação histórica do direito dos quilombolas na ANC, um direito não expresso na Constituição brasileira, embora seja um dos mais proeminentes direitos do homem. Tal valor jusfundamental supremo, cuja imprescritividade se impõe em toda sua pujança, concerne à liberdade do ser humano de não ser escravizado.

De fato, influenciou decisivamente no debate constituinte a ideia de que a Abolição da escravatura havia sido um processo formal e inacabado, de vez que não foi acompanhado de nenhuma reparação pelos graves danos sofridos ou políticas públicas de desenvolvimento direcionadas aos ex-escravos, que tivessem o condão de 
contribuir para a restauração da dignidade das pessoas lesadas (Prioste, Alves, Camerini, 2011, p. 299).

Com essa compreensão de que as terras dos remanescentes dos quilombos materializam reparação pelo crime de lesa humanidade consistente na escravidão, dou por encerrada essa pequena exposição dos fundamentos e do conteúdo do direito enfocado, com a seguinte assertiva de efeito exponencial: a garantia de titulação das terras remanescente de quilombos é dedutível do direito humano de não ser escravizado (art. $4^{\circ}$ da Declaração Universal dos Direitos Humanos).

Em conclusão, é patente que a regra insculpida no artigo 68 concretiza uma gama de princípios jurídicos, normas programáticas e direitos fundamentais consagrados constitucionalmente os quais, no caso das comunidades quilombolas, convergem para a garantia de seus territórios tradicionais. Por tudo isso - e pelo fato de ser um direito positivado na Constituição Federal -, há boas razões para sustentar que esse direito ostenta conteúdo e ocupa posição de verdadeiro direito humano fundamental no sistema constitucional brasileiro. ${ }^{17}$

\section{O Tribunal Constitucional e a Afirmação histórica dos DIREITOS FUNDAMENTAIS NA IDADE DA DEMOCRACIA CONSTITUCIONAL: O CASO DOS QUILOMBOS}

Malgrado o elevado peso dos argumentos e fundamentos suprarreferidos, é preciso sublinhar a contradição empírica de que não é pacífica a opinião de que os quilombos são, de fato, direitos fundamentais. A doutrina jurídica sobre o tema é lacunosa, como constatei da análise dos manuais de direito constitucional disponíveis no mercado editorial (Camerini, 2010, p. 135ss) e - até como consequência desse primeiro dado -, a jurisprudência é flutuante, muito embora a preciosa pesquisa de Luísa Andrade Corrêa (2009, p. 11) tenha observado uma tendência estatística que aponta a aplicação imediata do artigo 68 pelo Judiciário brasileiro, diretamente ou por intermédio do Decreto $n^{\circ} 4.887 / 03$ e das Instruções Normativas do Incra.

A explicação dessa contradição nos remete a perquirir as reais causas determinantes da consagração de novos direitos fundamentais e, desde logo, sustentar que: quaisquer razões que venham a prevalecer como justificação da classificação ou não dos quilombos dentro deste rol subordinam-se, ao fim e ao cabo, à tese da historicidade dos direitos do homem, como, de resto, também acontece com a definição do conteúdo desses direitos.

Essa teoria subjaz toda argumentação aqui desenvolvida e pressupõe a impossibilidade de determinação de um fundamento absoluto dos direitos do homem, válido universalmente e em todas as épocas. Antes ela crê que a multiplicação dos direitos do homem, sobretudo no período pós- $2^{a}$ Guerra Mundial, está assentada em consensos contextualmente construídos cujas condições históricas de possibilidade são 
determinadas por diversos fatores relativos, como: o aparecimento de novos carecimentos decorrentes das transformações sociais, por um lado, e de novos meios, inclusive tecnológicos, para satisfazer as necessidades humanas, por outro, além de ser essa progressão animada pela dialética própria das lutas dos movimentos sociais na justificação e exigência dos direitos que acreditam possuir. A tese da historicidade, defendida de modo insuperável por Norberto Bobbio (1992), assevera que não é suficiente apresentar boas razões para a defesa dos direitos fundamentais, mas o avanço na sua concretização depende, acima de tudo, de uma correlação favorável de forças históricas.

Para o objetivo deste artigo, importa especialmente anotar que, no conjunto de circunstâncias sócio-históricas que determinam a afirmação ou a negação de direitos fundamentais, talvez a condição mais relevante, na idade do constitucionalismo democrático, seja o posicionamento do Tribunal Constitucional. A lição de Alexy (1993, p. 23), nesse sentido, é plena de propriedade: "Lo que hoy son los derechos fundamentales es definido, principalmente, sobre la base de la jurisprudencia del Tribunal Constitucional Federal”.

Posta nesses termos a questão, consegue-se vislumbrar que, no quadro das contingências históricas suficientes para a afirmação dos remanescentes de quilombos como sujeitos de direitos fundamentais específicos, a decisão do STF na ADIn $n^{\circ}$ 3.239-9 repercutirá de maneira determinante sobre o campo dos direitos quilombolas, em razão do lugar de extrema proeminência que o tribunal ocupa na democracia brasileira. Logo, podemos colocar sob hipótese o seguinte: (1) estamos diante da possível emergência histórica de um novo sujeito de direitos fundamentais, trazido à lume pela Constituição de 1988: os remanescentes das comunidades dos quilombos; (2) O STF, na qualidade de instituição competente para proferir a última palavra sobre a interpretação das normas constitucionais, pode figurar, nesse processo, como instância de afirmação, desconhecimento - sobretudo se não enfrentar o mérito da questão - , ou de sufocamento desse sujeito de direito.

\section{A Questão da eficácia do ARTigo 68}

Que as terras quilombolas possuem conteúdo jusfundamental, não é difícil sustentar, no nível do discurso racional que parte da premissa de uma democracia inclusiva social, econômica e culturalmente, como se pretende a brasileira. O nó crítico reside no problema da eficácia dos direitos fundamentais que requerem prestações positivas do Estado para se realizarem, sendo esse o caso das comunidades remanescentes.

Para evitar a aplicabilidade imediata do artigo 68 do ADCT, o principal argumento do autor da ADIn n ${ }^{0}$ 3.239-9 insiste em situar essa norma na classe das normas de eficácia limitada, que, no essencial, se definem pela dependência de uma atuação do legislador para produzirem efeitos sobre os interesses que regulam. 
No caso particular do artigo 68, a indispensabilidade de lei ordinária é vista não como decorrente de ressalva expressa na constituição (reserva legal), mas principalmente devido à existência de conceitos indeterminados no enunciado normativo, cuja densificação semântica seria monopólio do legislador. Nesse quadro, o presidente da República, ao expedir o Decreto $\mathrm{n}^{\circ} 4.887 / 03$, teria legislado ex novo, violando, por conseguinte, o princípio da separação dos Poderes.

A tese contrária, por sua vez, sustenta a tese da aplicabilidade imediata do preceito constitucional e que o Decreto $n^{\circ} 4.887 / 03$ seria mera norma de instrumentalização de um direito constitucional com contornos bem definidos, conforme, aliás, o próprio artigo 68 ordena à Administração Pública ("devendo o Estado emitir-lhes os títulos respectivos"), sem ao menos mencionar o Poder Legislativo.

Forte na defesa dessa posição, o procurador da República Walter Claudius Rothenburg (2008, p. 461) assevera que o dispositivo do artigo 68 ostenta elementos suficientes para permitir sua execução imediata, o que vedaria a sua inclusão na categoria das normas de eficácia limitada.

(...) a aplicabilidade imediata (eficácia jurídica plena) é evidente e ressalta já da redação do dispositivo. Estão suficientemente indicados, no plano normativo, o objeto do direito (a propriedade definitiva das terras ocupadas), seu sujeito ou beneficiário (os remanescentes das comunidades dos quilombos), a condição (a ocupação tradicional das terras), o dever correlato (reconhecimento da propriedade e emissão dos títulos respectivos) e o sujeito passivo ou devedor (o Estado, Poder Público). Qualquer leitor bem-intencionado compreende tranquilamente o que a norma quer dizer, e o jurista consegue aplicá-la sem necessidade de integração legal.

O raciocínio é irrespondível, pois acentua que o artigo 68 demarca claramente a hipótese e condições de sua incidência e a consequência jurídica correspondente, apresentando, por um lado, estrutura normativa de elevada concretude, mas, por ser também dotado de estrutura normativa de elevada complexidade, não poderá jamais ser concretizado através do método positivista da subsunção, o que não inviabiliza, de modo algum, a sua aplicabilidade imediata, por meio dos recursos da hermenêutica concretista da Constituição.

A utilização da técnica legislativa das cláusulas gerais - gênero do qual os conceitos indeterminados são espécie (Barroso, 2009, p. 312) - permite que argumentação jurídica tópico-problemática e principiológica se aloje em espaços dantes governados unicamente pela estreiteza da argumentação jurídica sistemático-dedutiva.

O conceito de problema, na Tópica de Viehweg (1979, p. 34), foi cunhado para designar situações complexas para as quais não há solução previamente programada as quais exigem, para sua decisão, além do conhecimento dos enunciados normativos, a análise de dados extraídos da realidade. Assim também, segundo Barroso, "a característica 
essencial das cláusulas gerais é emprego de linguagem intencionalmente aberta e vaga, de modo a transferir para o intérprete o papel de completar o sentido da norma, à vista dos elementos do caso concreto" (Barroso, 2009, p. 312). E continua o autor: "atribuir sentido a um conceito indeterminado envolve uma atuação predominantemente técnica, baseada em regras de experiência, em precedentes ou, eventualmente, em elementos externos ao Direito" (Barroso, 2009, p. 313).

Para esse estudo, interessa menos a definição das cláusulas gerais e conceitos indeterminados do que a sua finalidade. Com efeito, a abertura semântica da linguagem jurídica é usada na argumentação do pólo ativo da ADIn $n^{\circ} 3.239-9$ como justificativa para impedir a produção de efeitos pela norma constitucional, quando, na verdade, as técnicas legislativas em questão deveriam servir para contornar os limites e problemas da produção legislativa num mundo complexo, plural e em constante transformação, permitindo, desse modo, ao Judiciário resolver casos relevantes pela via argumentativa.

A percepção de Alexy, melhor que nenhuma outra, deve servir para firmar de uma vez por todas que a textura aberta é inerente à linguagem jurídica e não pode servir, por si só, para inviabilizar a concretização do direito:

Desde luego, las dificuldades en la determinación del contenido exacto de derechos, al igual que la precisión de un concepto muy impreciso, no son algo insólito en la jurisprudencia y en la ciencia del derecho. Por lo tanto, la tesis de la justiciabilidad deficiente tiene que hacer valer algo más fuera de la imprecisión semántica y estructural de los derechos fundamentales sociales, es decir, la imposibilidad de llegar com medios especificamente jurídicos a una determinación exacta del contenido y estructura de derechos fundamentales sociales abstractamente formulados. Tiene que sostener que el derecho no ofrece pautas suficientes para ello (Alexy, 1993, p. 490).

Bem se vê, diante disso, que a progressiva utilização de conceitos indeterminados e princípios, que permitem maior amplitude hermenêutica reflete "a maior complexidade da vida moderna, assinalada pela pluralidade de projetos existenciais e visões de mundo, que comprometem as sistematizações abrangentes e as soluções unívocas para os problemas" (Barroso, 2009, p. 309).

Contudo, embora seja certo que não se pode negar eficácia ao artigo 68, a partir do argumento fraco de sua imprecisão semântica, também é correto que não há fórmulas fáceis para se responder à questão do grau de eficácia dos direitos constitucionais. Canotilho andou bem ao alertar que a tarefa de indicar quais são as “'normas constitucionais abertas' e quais as 'normas constitucionais densas' não é uma tarefa suscetível de ser reconduzida a esquemas fixos e totalizantes" (Canotilho, 1993, p. 189). No mesmo passo, Coelho (2000, p. 41) ressaltou, com perspicácia, que "não existe um critério que permita identificar, com segurança, 
quais dispositivos constitucionais podem ser reputados autoaplicáveis e quais outros dependem de regulamentação”.

Diante disso, e para que não se resolva em mero ato de poder, essa questão deverá ser alvo de atenciosa apreciação no julgamento da ADIn n ${ }^{\circ}$ 3.239-9 e sua definição dependerá, em grande medida, da teoria ou do conceito do que seja Direito (como ciência), o qual vier a prevalecer no Excelso Pretório, além da metodologia hermenêutica a ser desenvolvida pelo Tribunal.

Chego assim à parte final deste artigo, com a seguinte pergunta, à qual depois volverei: Qual a relação entre os quilombos e a teoria do direito?

\section{A disputa Pelos legítimos CRitérios hermenêUticos (E A HIPÓTESE DA PONTA DO ICEBERG)}

Pelo menos desde Haberlë (2002), a ciência jurídica assume que a interpretação constitucional tem lugar no interior da esfera pública e se procede debaixo da pressão de diversas agências políticas nela inseridas. Esse fenômeno, em princípio, é salutar para fundamentar a legitimidade democrática da jurisdição constitucional, contanto que se garanta aos interessados no processo a representatividade adequada e o direito de participação livre de coerções e distorções.

No momento de se pronunciar sobre um caso concreto, entretanto, a retórica judicial tende a invisibilizar o assinalado aspecto político da jurisdição constitucional através da referência aos dispositivos legais, precedentes e doutrinas sedimentadas no campo, de molde a dotar o decisum da aparência mais neutra e impessoal possível.

No contexto da ADIn n ${ }^{\circ} 3.239$, a tensão entre democracia e jurisdição constitucional vê-se tanto mais acirrada na medida em que tarda o pronunciamento da Corte sobre as dezenas de pedidos formalizados de realização de audiência pública sobre o caso, não obstante ser patente a complexidade técnica e científica da questão, a exigir necessariamente o pronunciamento de antropólogos e historiadores, bem como diante do anunciado impacto econômico, político e ambiental de envergadura nacional da decisão da causa.

Diante disso, pergunto: De que modo se produz o efeito de desconhecimento (méconnaissance) - na expressão de Bourdieu (2009, p. 212) - que consiste em deslocar para algum lugar fora dos autos a carga política que constitui, circunda e orienta as decisões, sobretudo em casos constitucionais difíceis e de grande repercussão social, a qual frequentemente não é enfrentada pelo Judiciário, sem prejuízo de continuar inegavelmente a produzir efeitos sobre o processo?

Coloco sob hipótese que isso ocorre, sem excluir outros fatores, porque os juízes exteriorizam ao público apenas o resultado fragmentado do processo cognitivo-decisório que desenvolvem na busca do direito das partes, mas não o processo integral. À sociedade democrática, o que se lhe dá a ver não é senão "a ponta do iceberg”. 
$\mathrm{O}$ aspecto político inerente à função jurisdicional situa-se, todavia, um passo antes do instante em que o julgador comunica ao espaço público o seu entendimento, justificando-o. O que proponho talvez seja a publicização do espírito judicante ou da totalidade do processo cognitivo-decisório, a tal ponto que o decisum abandone a forma de um "entendo assim porque" para assumir a forma mais democrática - e isso quer dizer transparência, publicidade, racionalidade dialógica -, de um "por que entendo assim? Entendo assim porque”.

Ainda por outras palavras, o momento determinante do processo decisório, que permanece muitas vezes silenciado no espírito do juiz, sem possibilidade de controle democrático ou de manifestação pelas partes, é a escolha de seus pressupostos teóricos e hermenêuticos, o que pode conduzir à necessidade de uma discussão mais ou menos profunda sobre a própria teoria política e constitucional geral que subjaz à deliberação judicial, como mostrou Dworkin (2002, p. 167ss).

Para isso também acena Haberlë, ao entender que "afigura-se evidente que requerentes e requeridos perseguem objetivos diversos no processo constitucional e, por isso, hão de eleger métodos diferenciados de interpretação, procurando abrigar o conteúdo da controvérsia dentro desses diferentes modelos ou métodos” (2002, p. 51).

Isso significa que, no caso concreto do artigo 68 do ADCT, a decisão pode variar conforme se defina se, no Brasil, estamos ou não estamos em um Estado Plural e Multicultural, onde vigora o constitucionalismo fraternal, exaltado no caso Raposa Serra do Sol.

Igualmente, parece claro que a eficácia ou esvaziamento do artigo dependem do modo como são interpretados. Assim, para chegar à tese que esvazia o artigo 68 de conteúdo e eficácia, o autor e respectivos amicus curiae desenvolvem processos interpretativos típicos da tradição hermenêutica positivista legalista do século XIX, levando a cabo principalmente leituras gramaticais e lógico-sistemáticas.

Essas vias hermenêuticas contêm as qualidades e defeitos da teoria do direito positivista, que lhes serve de supedâneo. Por um lado, promovem segurança para as relações sociais e econômicas. Por outro, a hermenêutica positivista legalista traz consigo o risco da esquizofrenia jurídica, visto que favorece a cisão entre o mundo jurídico e o mundo da vida.

$\mathrm{Na}$ medida em que conduz o intérprete à fragmentação do real, a hermenêutica positivista tem se revelado socialmente excludente, porquanto nega proteção jurídica a situações fáticas não imediatamente dedutíveis da letra da lei ou não automaticamente enquadráveis na lógica sistêmica.

O grito dos povos, os conflitos sociais complexos e multitudinários, as diferenças culturais e os direitos das minorias, quando submetidos a esquemas interpretativos lógico-gramaticais, traduzem-se em ruídos indecifráveis, em irracionalidade, e muitas vezes têm para si reservado, no decisum, o capítulo designado "da impossibilidade jurídica do pedido”. 
Vai nessa toada a afirmação do Partido Democratas, na petição inicial da ADIn $n^{\circ} 3.239$, referindo à autodefinição como via de definição de quem são os remanescentes de quilombo, de que "submeter a qualificação constitucional a uma declaração do próprio interessado nas terras importa radical subversão da lógica constitucional”. ${ }^{18}$ E eis há, no final das contas, alguma lucidez nessa afirmação que, embora se preste à afirmar uma determinada lógica autorreferencial contra os direitos das pessoas, de certo modo nos permite confirmar que:

(...) a aceitação dos termos em que é feita a enunciação dos direitos territoriais quilombolas e de outros grupos sociais pelo direito étnico, ameaça abalar as leis de pronunciamento do discurso jurídico dominante, como têm mostrado Shiraishi Neto (2006, 2007a), máxime quando o reconhecimento e atribuição de normatividade às tradições de grupos étnicos - como os quilombolas - retira parte do controle sobre produção e interpretação do direito das mãos dos profissionais do direito ou, ainda, quando o regime de apropriação da terra praticado pelos remanescentes dos quilombos contraria frontalmente a disciplina civilista da propriedade (Camerini, 2010, p. 32).

Nesse sentido, afirmei, em outra oportunidade (Camerini, 2010, p. 158), que não faz sentido nenhum interpretar os quilombos a partir de um conceito de direito, de matriz positivista, que o reduz à noção de segurança jurídica. Isso porque essa categoria encontra seu substrato na ideia de previsibilidade, que pode ser entendida como a garantia da repetição do passado no futuro.

Ora, não é preciso dizer do que é feito o passado dos remanescentes de quilombos: sequestro, escravidão, pobreza e expulsão de suas terras, de modo que, nesse caso, o passado é aquilo que deve ser negado, e a segurança jurídica, paradoxalmente, aguarda os quilombolas em algum lugar do futuro.

Ao contrário da interpretação que esvazia de eficácia o artigo 68, para o Governo Federal, MPF e amicus das comunidades quilombolas, que se valem dos cânones da hermenêutica constitucional e pós-positivista, além de princípios do direito étnico, a conclusão resulta sobremodo distinta.

As diferenças marcantes entre a hermenêutica clássica - da Escola da Exegese aos cânones de Savigny (1878, p. 150/151) - e a nova residem, primeiro, no fato desta, a partir da relativização drástica do geneticismo e do voluntarismo, seja objetivo (mens legis) ou subjetivo (mens legislatoris), direciona todo o seu instrumental cognitivo, agora mais complexo (à lei e às regras somam-se as normas-princípios e os conceitos indeterminados), não para a busca de uma coerência sistêmica interna, mas para a realidade, representada nos conceitos de problema (Viehweg, 1979), âmbito normativo (Müller, 2010) e hard case (Dworkin, 2002). 
Em segundo lugar, é traço fundamental da nova hermenêutica constitucional o abandono do formalismo e a sua orientação para a concretização dos direitos fundamentais, característica expressa em noções como a de vontade de constituição (Hesse, 1991), como a de "levar os direitos a serio" (Dworkin, 2002) e, sobretudo, no princípio da máxima efetividade (Canotilho, 1993, p. 227).

Ou seja, o instrumental hermenêutico à disposição do intérprete, que dantes funcionava como cadeia lógica da qual não podia escapar uma decisão judicial idêntica tão somente a si própria, ora transforma-se numa porta aberta entre o ordenamento jurídico e o sofrimento humano. Os argumentos histórico, teleológico e sociológico são, nessa esteira, objeto de releitura sob a óptica de uma hermenêutica da garantia de direitos no presente e in concreto. A coerência passa a ser medida não apenas segundo a lógica formal da não contradição e da completude, mas segundo a lógica material fundada da efetividade das normas constitucionais e na eficiência do desempenho da função social do direito.

Enfim, se quisermos ouvir o que tem a dizer essa hermenêutica constitucional, no caso da interpretação do artigo 68 do ADCT, ela nos dirá: (1) não se deve atribuir-lhe significado que esvazie sua eficácia, por exemplo, exigindo-se provas impossíveis da condição de quilombola, atribuindo ao dispositivo a pecha de eficácia limitada ou norma programática ou impedindo a desapropriação para titulação de terras quilombolas; (2) deve-se enfrentar a questão da mutação constitucional da categoria quilombo; (3) há que se preencher os conceitos indeterminados de "remanescentes de comunidades de quilombos" e "propriedade definitiva de suas terras" com dados extraídos da realidade.

A isso, acrescentará a hermenêutica do direito étnico: (1) é ofensivo à liberdade cultural o ato de classificar um grupo étnico a partir de critérios exógenos, seja pela ciência ocidental, pela burocracia estatal ou pela uniformidade da lei; (2) é lesivo ao patrimônio cultural afro-brasileiro aplicar à propriedade quilombola o regime jurídico da propriedade civil ocidental; (3) a decisão da ADIn $\mathrm{n}^{\circ}$ 3.239-9 deve orientar-se por um princípio de intervenção mínima do Direito na organização étnica própria dos grupos.

\section{CONSIDERAÇÕES FINAIS}

Não faltam razões para que o Supremo Tribunal Federal reconheça a fundamentabilidade do direito das comunidades quilombolas às terras que tradicionalmente ocupam. Os quilombos do presente encarnam um suporte fático capaz de atrair a proteção do direito à dignidade humana, do direito à liberdade cultural, do princípio da igualdade material e mesmo do direito de não ser escravizado sem que isso gere um direito à reparação.

A complexidade desse direito é, entretanto, a principal dificuldade com que se defronta a Corte Constitucional, na medida em que o artigo 68 introjeta categorias 
inéditas que abalam a capacidade de leitura do sistema jurídico e dos operadores do direito.

A definição dos sujeitos de direitos designados remanescentes das comunidades dos quilombos e dos territórios quilombolas, a partir do critério da autodefinição, consagrado na Convenção 169 da OIT, parece abalar as regras de enunciação de um discurso jurídico colonizado pela noção de segurança jurídica, voltada para a repetição do passado no presente e pouco adequada às funções jurídico-constitucionais de transformação e construção de um futuro livre, justo e solidário.

O regime jurídico-civilista da propriedade, imaginado e vivido como universal, vê-se igualmente pressionado ante a contemplação de um modo de apropriação - a propriedade quilombola -, não idêntico a si, visto que baseado no uso coletivo e definitivo do território, o que redunda na subtração de importantes parcelas do espaço fundiário do mercado de terras.

Diante dessas perplexidades, o STF deverá levar a sério a questão relativa à eficácia do artigo 68, cuja solução perpassa pela concretização dos conceitos jurídicos supraindicados. Porém, com os elementos fáticos e jurídicos de que dispõe, é possível ao Supremo realizar essa densificação que é fundamental para a efetividade da norma? Ora, direi, depende da teoria do direito que o tribunal adotar.

E com isso concluo, retornando à pergunta de alhures: Qual a relação entre os quilombos e a teoria do direito? Ao que respondo de imediato: a relação está em que pode não ser muito fácil, para o STF, deduzir a constitucionalidade do Decreto 4.887/03 do texto do artigo 68 do ADCT; em contrapartida, pode ser muito mais fácil argumentar, com base em princípios e direitos humanos fundamentais, em favor da constitucionalidade do decreto.

No aguardo desse pronunciamento, jazem as famílias quilombolas, inclusive aquelas moradoras dos quilombos do Baixo Amazonas, onde realizei minha pesquisa de campo. Em suas paragens ao redor do lago do Maicá ou próximas à boca do rio Ituqui, elas talvez nunca tenham imaginado que estariam acompanhando o debate teórico dos juristas, ${ }^{19}$ como de fato estão hoje a fazer, de uma maneira ou de outra, e por um motivo muito singelo: provavelmente, as comunidades quilombolas não estão interessadas na questão de se o Direito é ou não uma ciência do tipo lógicodedutivo ou tópico-problemático e hermenêutico; mas elas, possivelmente, estão interessadas em se a Corte Suprema do Brasil adota ou não uma teoria do direito que lhes atribui ou expropria direitos.

: ARTIGO APROVADO (01/06/2012) : RECEBIDO EM 12/09/2011 
1 Após o recebimento e aprovação deste artigo, o julgamento da ação veio a iniciar-se, no dia 18.04.2012, sendo prolatado o voto do relator ministro Cezar Peluso, que acolheu rigorosamente todos os pedidos autorais. Prima facie, negou as dezenas de pedidos de audiência pública, entendendo ser a questão unicamente de direito e não apresentar complexidade técnica. Afastou, em seguida, a alegação de ofensa reflexa à Constituição, qualificando o Decreto 4.887/2003 como decreto autônomo, com pretensões de regulamentar diretamente a Lei Maior, superando também a preliminar que afirmava que o autor não se desincumbira do ônus de impugnar do Decreto 3.912/2001, revogado pelo Decreto atacado, o que ensejaria a verificação do efeito repristinatório. No mérito, afirmou que administração pública não pode, sem lei, impor obrigações ou restringir direitos de terceiros, inclinando-se, nesse sentido, pela tese da eficácia limitada do artigo 68 do ADCT, que parte do pressuposto de que a Constituição não teria já criado e restringido direitos. Posicionou-se Peluso, arrimado em dicionários, favorável a uma concepção dita histórica de quilombo, não bem explicitada em seu voto, a qual teria sido a visada pelo constituinte, qualificando como "metajurídicos" os trabalhos jurídicos e antropológicos que analisaram o termo. Fixou a data de 05.10.1988 como marco temporal a ser observado para aferição dos sujeitos do direito constitucional às terras quilombolas. Afirmou, ademais, a natureza individual e disponível desse direito, não havendo que se falar em titulação coletiva e na impenhorabilidade, inalienabilidade e imprescritibilidade das terras quilombolas. Reputou, em consequência dessa linha interpretativa, a inconstitucionalidade dos critérios da autodefinição e da atribuição aos quilombolas das terras por eles tradicionalmente ocupadas, sendo estas as necessárias à sua reprodução física, social, econômica e cultural. Por fim, negou a possibilidade jurídica de ocorrerem desapropriações de propriedade privadas no processo de efetivação do artigo 68, atribuindo-lhe, dessarte, sentido jurídico semelhante ao de uma usucapião centenária, com a peculiaridade de poder incidir sobre imóveis públicos. Citou, ao final, reportagens que demonstrariam que as "usurpações" promovidas pelo Decreto contestado estariam a contribuir para o aumento dos conflitos agrários e sustentou que nem mesmo as comunidades quilombolas estariam satisfeitas com o Decreto 4.887, visto que padecia de grave ineficácia. Modulou os efeitos da decisão para considerar válidos os títulos até o presente emitidos. Ver: Informativo 662 do STF. Disponível em: www.stf.jus.br. Acesso em: 01 mai. 2012. O pedido de vista da Ministra Rosa Weber, logo em seguida ao voto do relator, bem como a postura absolutamente radical adotada por Peluso, sugerem, todavia, que a questão continua em aberto, e aumentam necessidade de discussão crítica sobre o tema específico dos direitos quilombolas e, sobretudo, dos direitos étnicos em geral.

2 Art. 68 do ADCT: Aos remanescentes das comunidades dos quilombos que estejam ocupando suas terras é reconhecida a propriedade definitiva, devendo o Estado emitir-lhes os títulos respectivos.

3 Ver autos da ADIn no 3.239-9. Disponível em: www.stf.jus.br. Acesso em: 14 jul. 2010.

4 Segundo Di Pietro (2003, p. 87), “o regulamento autônomo ou independente inova na ordem jurídica, porque estabelece normas sobre matérias não disciplinadas em lei; ele não completa nem desenvolve nenhuma lei prévia”.

5 Ver autos da ADIn n 3.239-9. Documento disponível em: www.stf.jus.br. Acesso em: 15 dez. 2010.

6 Art. 216, $\S 1^{\circ}$, da Constituição Federal: O Poder Público, com a colaboração da comunidade, promoverá e protegerá o patrimônio cultural brasileiro, por meio de inventários, registros, vigilância, tombamento e desapropriação, e de outras formas de acautelamento e preservação.

7 Cf., por todos, Shiraishi Neto (2007).

8 Essa ainda não internalizada pelo Brasil, embora assinada.

9 STF, Pleno, Ação popular no 3.388, Rel. Min. Carlos Ayres Britto, DJ n. 120, Publicação: 01.07 .2010 .

10 Art. $2^{\circ}$, caput, $\S 1^{\circ}$, do Decreto $n^{\circ}$ 4.887/03: Consideram-se remanescentes das comunidades dos quilombos, para os fins deste Decreto, os grupos étnico-raciais, segundo critérios de autoatribuição, com trajetória histórica própria, dotados de relações territoriais específicas, com presunção de ancestralidade 
negra relacionada com a resistência à opressão histórica sofrida. (...) $\S 1^{\circ}$ - Para os fins deste Decreto, a caracterização dos remanescentes das comunidades dos quilombos será atestada mediante autodefinição da própria comunidade.

11 STF, Pleno, Ação popular n 3.388, Rel. Min. Carlos Ayres Britto, DJ n. 120, Publicação: 01.07.2010.

12 Cf. Yamada e Villares (2010, p. 147).

13 STF, Pleno, Ação popular n 3.388, Rel. Min. Carlos Ayres Britto, DJ n. 120, Publicação: 01.07.2010.

14 STF, Pleno, Ação popular n 3.388, Rel. Min. Carlos Ayres Britto, DJ n. 120, Publicação: 01.07.2010.

15 Projeções feitas com base no número atual de comunidades quilombolas tituladas (189) e na extensão total dessas áreas $(987.935,9873 \mathrm{ha})$, estimando que exista um total entre 3.500 e 5.000 quilombos no Brasil. Dados do Incra, disponíveis em: www.incra.gov.br/. Acesso em: 09 set. 2011.

16 Dados do Instituto Socioambiental (ISA). Disponível em: http://pib.socioambiental.org/pt/c/ 0/1/2/situacao-juridica-das-tis-hoje. Acesso em: 09 set. 2011.

17 Essa a conclusão dos estudos mais aprofundados sobre o tema: cf. Treccani (2006); Duprat (2007); Rothenburg (2008); Rios (2007); Silva (1997b), para citar somente estes.

18 Ver autos da ADIn n 3.239-9. Disponível em: www.stf.jus.br. Acesso em: 15 dez. 2010.

19 No VII Encontro das Comunidades Negras de Santarém, realizado nos dias 19 e 20 de outubro de 2009, na Comunidade Quilombola de Murumuru, foi discutido o andamento da ADIn $\mathrm{n}^{\circ} 3.239$, as potências políticas e econômicas envolvidas e a influência decisiva que o julgamento dessa ação terá para o Movimento Quilombola em âmbito nacional. Evento esse que acompanhei por ocasião de minha pesquisa de campo.

\section{REFERÊNCIAS BIBLIOGRÁFICAS}

ALEXY, Robert. Teoria de los Derechos Fundamentales. Madrid: Centro de Estudos Constitucionales, 1993. ALMEIDA, Alfredo Wagner Berno de. Nas bordas da política étnica: os quilombos e as políticas sociais. Boletim Informativo NUER, Florianópolis, v. 2, n. 2, p. 15-44, 2005.

ARRUTI, José Maurício Andion. Mocambo: antropologia e história do processo de formação quilombola. Bauru: Edusc, 2006.

BARROSO, Luís Roberto Barroso. Curso de direito constitucional contemporâneo. São Paulo: Saraiva, 2009. BOBBIO, Norberto. A era dos direitos. Traduzido por Carlos Nelson Coutinho. Rio de Janeiro: Campus, 1992. BOURDIEU, Pierre. O poder simbólico. Traduzido por Fernando Tomaz. 12. ed. Rio de Janeiro: Bertrand Brasil, 2009.

CAMERINI, João Carlos Bemerguy. Discursos jurídicos acerca dos direitos territoriais quilombolas: desmascarando os colonialismos da épistémè jurídica. Dissertação de mestrado apresentada ao Programa de Pós-graduação em Direito Ambiental da Universidade do Estado do Amazonas. Manaus: UEA, 2010. CANOTILHO, José Joaquim Gomes. Direito Constitucional. 6. ed. rev. Coimbra: Almedina, 1993. CINTRA, Antonio Carlos de Araújo; GRINOVER, Ada Pellegrini; DINAMARCO, Cândido Rangel. Teoria geral do processo. 20. ed. rev. e atual. São Paulo: Malheiros, 2004.

CORRÊA, Luiza Andrade. Comunidades quilombolas no Judiciário brasileiro: análise comparativa da jurisprudência. Monografia apresentada à Escola de Formação da Sociedade Brasileira de Direito Público. São Paulo: SBDP, 2009. Disponível em: www.sbdp.org.br. Acesso em: 16 dez. 2010.

DI PIETRO, Maria Sylvia Zanella. Direito administrativo. 16. ed. São Paulo: Atlas, 2003.

DUPRAT, Deborah. Breves considerações sobre a inconstitucionalidade do Decreto 3.912/2001. In: Deborah Duprat. (Org.) Pareceres jurídicos - Direito dos povos e das comunidades tradicionais. Manaus: UEA, 2007, p. 31-40. 
DWORKIN, Ronald. Levando os direitos a sério. Traduzido por Nelson Boeira. São Paulo: Martins Fontes, 2002.

FOUCAULT, Michel. A ordem do discurso. Aula inaugural no Collège de France, pronunciada em 02.12.1970. 5. ed. Traduzido por Laura Fraga de Almeida Sampaio. São Paulo: Edições Loyola, 1999.

HABERLË, Peter. Hermenêutica constitucional. A sociedade aberta dos intérpretes da Constituição: contribuição para a interpretação pluralista e "procedimental" da Constituição. Traduzido por Gilmar Ferreira Mendes. Porto Alegre: Sergio Antonio Fabris Editor, 2002.

HABERMAS, Jürgen. Teoria de la Acción Comunicativa, II: Crítica de la Razón Funcionalista. 1. ed., 3. reimpr. Madrid: Taurus Humanidades, 1992.

HESSE, Konrad. A força normativa da Constituição (Die Normative Kraft der Verfassung). Traduzido por Gilmar Ferreira Mendes. Porto Alegre: Sergio Antonio Fabris, 1991.

MARINONI, Luiz Guilherme. A jurisdição no Estado constitucional. Biblioteca Virtual do Supremo Tribunal de Justiça, 2006. Disponível em: http://bdjur.stj.jus.br/dspace/handle/2011/2174. Acesso em: 17 dez. 2010.

MENDES, Gilmar Ferreira. Âmbito de proteção de direitos fundamentais e as possíveis limitações. In: Gilmar Ferreira Mendes; Inocêncio Mártires Coelho; Paulo Gustavo Gonet Branco. Hermenêutica constitucional e direitos fundamentais. Brasília: Brasília Jurídica, 2000.

MÜLLER, Friedrich. Metodologia do direito constitucional. 4. ed. rev., atual e ampl. São Paulo: Revista dos Tribunais, 2010.

PIOVESAN, Flávia. Direitos sociais, econômicos e culturais e direitos civis e políticos. Sur - Rev. Internacional de Direitos Humanos, ano 1, n. 1, 2004.

PRIOSTE, Fernando G. V.; ALVES, Carolina C. N.; CAMERINI, João Carlos B. Quem tem medo da Constituição Federal? Quilombolas e direito ao território. In: Sérgio Sauer; Wellington Almeida. (Orgs.) Terras e territórios na Amazônia: demandas, desafios e perspectivas. Brasília: Editora UnB, 2011. ROTHENBURG, Walter Claudius. Direitos dos descendentes de escravos (remanescentes das comunidades de quilombos). In: Daniel Sarmento; Daniela Ikawa; Flávia Piovesan. (Coord.) Igualdade, diferença e direitos humanos. Rio de Janeiro: Lumen Juris, 2008.

SANTOS, Boaventura de Sousa. Para uma sociologia das ausências e uma sociologia das emergências. Rev. Crítica de Ciências Sociais, n. 63, p. 237-280, out. 2002.

SAVIGNY, Friedrich Carl von. Sistema del Derecho Romano Actual. Madrid: F. Góngora y Compania, 1878. SHIRAISHI NETO, Joaquim. A particularização do universal: povos e comunidades tradicionais em face das declarações e convenções internacionais. In: Joaquim Shiraishi Neto. (Org.) Direito dos povos e das comunidades tradicionais no Brasil: declarações, convenções internacionais e dispositivos jurídicos definidores de uma política nacional. Manaus: UEA, 2007.

. O Direito das Minorias: passagem do "invisível” real para o "visível” formal? Tese de doutorado apresentada ao Programa de Pós-graduação em Direito das Relações Sociais da Universidade Federal do Paraná. Curitiba: UFPR, 2004.

SILVA, Dimas Salustiano da. Apontamentos para compreender a criação e regulamentação do artigo 68 do Ato das Disposições Constitucionais Transitórias de 1988. Boletim Informativo NUER, Florianópolis, v. 1, n. 1, p. 11-27, 1997a.

Constituição e diferença étnica: o problema jurídico das comunidades negras remanescentes de quilombos no Brasil. Boletim Informativo NUER, Florianópolis, v. 1, n. 1, p. 51-64, 1997b.

SILVA, José Afonso da. Aplicabilidade das normas constitucionais. 7. ed. São Paulo: Malheiros, 2007. TRECANNI, Girolamo Domenico. Terras de quilombo: caminhos e entraves do processo de titulação. Belém: Secretaria Executiva de Justiça/Programa Raízes, 2006.

VIEHWEG, Theodor. Tópica e jurisprudência. Traduzido por Tercio Sampaio Ferraz Jr. Brasília: Departamento de Imprensa Nacional, 1979.

YAMADA, Erica Magami; VILLARES, Luiz Fernando. Julgamento da Terra Indígena Raposa Serra do Sol: todo dia era dia de índio. Revista DIREITO GV, São Paulo, v. 6, n. 1, Jun. 2010. Disponível em: www. scielo.br/scielo.php?script $=$ sci_arttext\&pid $=\mathrm{S} 1808-24322010000100008 \& \operatorname{lng}=\mathrm{en} \& \mathrm{nrm}=\mathrm{iso}$. Acesso em: 05 abr. 2012. 
182 : OS QUILOMBOS PERANTE O STF: A EMERGÊNCIA DE UMA JURISPRUDÊNCIA DOS DIREITOS ÉTNICOS

\section{João Carlos Bemerguy Camerini}

Rua Galdino Veloso, n. 450, sala 5 Centro - 68005-070 Santarém - PA - Brasil joaolaterradedireitos.org.br
Mestre em DiReITOS DA SócIO-BIODIVERSIDADE Pela Universidade do Estado do Amazonas (UEA) 